\title{
Age-old wisdom concerning cell-based therapies with added knowledge in the stem cell era: our perspectives
}

This article was published in the following Dove Press journal:

Stem Cells and Cloning:Advances and Applications

3 April 2013

Number of times this article has been viewed

\author{
Senthilkumar Preethy ${ }^{1,2}$ \\ Sudhakar John' \\ Jegatheesan Saravana \\ Ganesh' \\ Thangavelu Srinivasan' \\ Hiroshi Terunuma ${ }^{3}$ \\ Masaru Iwasaki ${ }^{4}$ \\ Samuel J Abraham ${ }^{1,4}$
}

'Nichi-In Centre for Regenerative Medicine, ${ }^{2}$ Hope Foundation Trust, Chennai, India; ${ }^{3}$ Biotherapy Institute of Japan, Tokyo, ${ }^{4}$ Yamanashi University School of Medicine, Chuo, Japan
Correspondence: Samuel JK Abraham Nichi-In Centre for Regenerative Medicine, PO Box 2278, Chennai 600026, Tamil Nadu, India

$\mathrm{Tel}+9 \mid 444232$ I 322

Fax +91 4424732186

Email drabrahamsj@ybb.ne.jp

\begin{abstract}
Among the various strategies providing a cure for illness, cell-based therapies have caught the attention of the world with the advent of the "stem cell" era. Our inherent understanding indicates that stem cells have been in existence since the birth of multicellular organisms. However, the formal discovery of stem cells in the last century, followed by their intricate and extensive analysis, has led to clinical and translational efforts with the aim of using them in the treatment of conditions which don't have a definitive therapeutic strategy, has fueled our interest and expectations. Technological advances in our ability to study their cellular components in depth, along with surface markers and other finer constituents, that were unknown until last century, have improved our understanding, leading to several novel applications. This has created a need to establish guidelines, and in that process, there are expressed understandings and views which describe cell therapy along lines similar to that of biologic products, drugs, and devices. However, the age-old wisdom of using cells as tools for curing illness should not be misled by recent knowledge, to make cell therapy using highly complex stem cells equal to factory-synthesized and reproducible chemical compounds, drugs, or devices. This article analyses the differences between these two entities from various perspectives.
\end{abstract}

Keywords: cell transplantation, drugs, regenerative medicine, stem cells

\section{Introduction}

In recent times, cell-based therapies have occupied a prominent position in the treatment of illness. Although this recent attention can be attributed mainly to the catchy terminology associated with "stem cells", cell-based therapies have been in clinical use for a long time, as evident from established procedures such as blood transfusion, ${ }^{1}$ bone marrow transplantation, ${ }^{2}$ and autologous transplantation of tissues, either with a pedicle with the vascular supply intact as in myocutaneous flap surgery, or without a vascular pedicle intact, as in skin transplantation. ${ }^{3}$ In all these procedures, it is now understood that a proportion of "stem cells" play an important role in producing beneficial results. ${ }^{4-6}$

In blood transfusion, the cells transfused are mostly mature adult cells which transiently take on the functions of cells involved in native hematopoiesis and then disappear, ${ }^{6}$ whereas in bone marrow transplantation, there are more stem cells, which replace the hematopoietic system of the patient and take over the responsibility for hematopoiesis; this could be one of the reasons why bone marrow transplantation came to be known as "hematopoietic stem cell transplantation" after the discovery of stem cells by Till and McCulloch in 1961. ${ }^{7,8}$ Within the spectrum of cell-based therapies, the ultimate is in vitro fertilization, where two germ cells of male and female origin are 
made to undergo fusion in a nonphysiological environment and then produce a potential life form, ie, an embryo which is transferred back to the native physiological environment of the uterus of the female gamete donor or a surrogate. ${ }^{9}$ The practice of in vitro fertilization has been successful since $1978,{ }^{9}$ with those born of an in vitro fertilization procedure having since produced children by normal physiological sexual reproduction. ${ }^{10}$

The recent increase in the number of cell-based therapies available, in addition to giving hope to those who are likely to benefit from them, has led to confusion when attempting to categorize them appropriately. According to published guidelines, ${ }^{11,12}$ cell-based therapies are presently considered in the same way as drugs, biologic products, and devices. However, drug terminology becomes contentious when applied to cellbased therapies. In this paper, we highlight a number of facts indicating that it would be more appropriate if autologous cell-based therapies using cells as a tool for treatment were considered as a clinical practice or procedure rather than as biologic products, drugs, or devices.

\section{Cell-based versus drug-based therapies \\ Active ingredients}

A drug is a chemical entity which, in the form of a tablet, capsule, or injectable fluid, in principle contains a defined quantity of the substance contained within a suitable carrier for stability and absorption. Based on the pharmacopeia, the contents are very clearly and meticulously packed and labeled, with a defined shelf life. Irrespective of where it is manufactured, if the drug has been produced following standardized international guidelines, it is understood to contain standardized ingredients in the same proportions and quantity wherever it is purchased.

However, in the case of cell therapy, the nature of the stem cell differs according to its source (ie, from bone marrow of the iliac crest, sternum, or peripheral blood), ${ }^{13}$ its contents (ie, whether the stem cells are of mesenchymal or hematopoietic origin), ${ }^{14}$ and its potency (ie, whether the source is embryonic or adult). ${ }^{15}$ Further, a cell cannot be described in terms of a single active ingredient (as is the case with a drug), and at present there is no defined shelf-life for these cells, given that the methods used for processing, culture, storage, and manipulation of the various types of cells have not been standardized worldwide. ${ }^{16-19}$ Even if such cells were standardized, cells obtained from one subject might behave differently from those obtained from another subject. The number of divisions a cell undergoes in vitro, which is outside the native physiological environment, may also affect its in vivo activity due to factors such as cell senescence. ${ }^{16-20}$ It should also be understood that a stem cell obtained from a young person may differ in activity from that obtained from an elderly person. ${ }^{20}$ Such factors do not need to be taken into account for a chemical entity, but are of importance in cell-based therapies.

\section{Bioavailability and excretion}

The bioavailability of any drug, whether administered orally or parenterally, is a key determinant of its potency. However, in the case of cells, the term bioavailability becomes a broader concept because cells injected into one part of the body might not reach another part of the body. ${ }^{21}$ Reasons for this include trapping of cells in the pulmonary capillary bed when they are injected intravenously ${ }^{22}$ and the fact that certain stem cells do not cross the blood-brain barrier, even though molecules secreted by these cells may cross this barrier. ${ }^{23}$ Once a drug is administered, its excretion through renal or other routes is clearly defined, and any precautions that are necessary as a result of its interactions with other drugs, as well as the effects of the drug in overdose, can be documented. Such definitions, including the term "half-life", cannot be applied to cells which, once injected into the body, may remain there until apoptotic death or other modes of cell degeneration occur. How long these cells remain in the body cannot be determined using current technology.

\section{Transformation and interactions}

In contrast with a drug, the bioavailability and excretion of which involves a single chemical entity and/or a metabolite, cells can undergo a variety of metabolic changes and become part of metabolism itself, thereby producing more than one substance and for an unknown duration. ${ }^{24}$ The mechanisms of action of most drugs are well established. However, stem cells, when injected, might produce their beneficial effects by multiple mechanisms, including paracrine action, differentiation into cells of a desired nature, and cell fusion, ${ }^{24}$ and cells not participating in any of these processes may degenerate. ${ }^{25}$ Thus, the mechanism of action of cells cannot be delineated in the same way as that for most drugs.

\section{Potential adverse effects}

Any drug with therapeutic activity also has varying degrees of adverse effects to some extent, and these reactions are known before regulatory approval is given. ${ }^{26}$ Many drugs have a known antidote or a counteracting component by which adverse reactions can be reversed or brought under control. ${ }^{27}$ 
In the case of cells, the duration of survival and functions in vivo are not well defined. Further, once released into the body, targeting them specifically and controlling their actions without damaging the surrounding tissues or organs is impossible.

\section{Dose standardization}

Drugs can be prepared in specific quantities, so their doses are measurable. After standardization in vitro, a likely dose range is ascertained based on the minimum lethal dose in animal studies, then tested for safety and efficacy in human studies. In the case of cells, there is no single active ingredient for which an appropriate dose can be calculated. The in vitro and in vivo efficacy of cells may differ markedly, and it is near impossible to create a physiological environment in vitro which mimics that found in vivo in terms of influencing the transformation or differentiation of cells. In addition, the fate of cells may be different according to the local environment, may vary from organ to organ, and according to the type of disease present in the dysfunctional or damaged organ. Examples include:

- Potential differences in the efficacy of cell therapy between two spinal cord injury cases because of differences in the local environment, eg, blood supply. ${ }^{28}$

- Variations in the intended function of the cells injected according to pathogenesis, eg, whether the patient has alcohol-induced hepatic cirrhosis or viral liver disease, given the hemodynamic differences that exist between these two liver diseases; ${ }^{29}$ the potential differences in efficacy of cell therapy in such circumstances need further study. ${ }^{30}$

- Differential therapeutic effects of injected cell therapy in an area of myocardium with intense inflammation post infarction versus another area without inflammation. ${ }^{31}$

- Differential therapeutic effects of injected cell therapy in an ischemic lower limb with infection versus one without infection, which are not addressed adequately in the literature.

Therefore, a drug may be considered as a single entity which, when injected into a multiple entity human body, has predictable results, ie, single $\times$ multiple, with effects in vivo that can be controlled using counteractive antidotes and strategies. However, a cell, which is a multiple entity by nature of its content and source, has the potential to undergo multiple interactions and changes inside the body and ultimately when it reaches its intended target, performs multiple functions which cannot be controlled with precision. Therefore, when a cell is injected into a human body, the result is multiple $\times$ multiple, and has a huge value as a result of the many combinations possible.

\section{Reproducibility}

Manufacturing of drugs follows the universal rule of reproducibility, whereby any given drug can be manufactured with the same precision anywhere in the world if the same established protocol is followed. However, in the case of cell-based therapies, variability exists for several reasons, including variations in the source from which the cells are obtained, the protocol followed, the duration of culture, the laboratory personnel involved, the mode of transport, and storage conditions. ${ }^{32}$ Apart from the simple fact that a living cell cannot be produced in the laboratory using commercially available reagents or chemicals, even cells which are multiplied in the laboratory using in vitro cultures from naturally-derived mother cells will develop senescence much faster than in vivo. ${ }^{33}$ Given that reproducibility is the hallmark of any experiment based on the permutation-based and combination-based science of today, cells cannot be reproduced in the laboratory in an artificial manner, so should not be equated with drugs.

\section{Discussion}

With the above hypothetical perspectives drawing a line of demarcation between drug-based and cell-based therapies, cells should not be placed in the same category as drugs. To arrive more precisely at how they should be categorized, it is worthwhile reviewing the treatment strategies in which the use of autologous and allogenic cells is well established, but without being categorized as drug therapy.

Blood transfusion has been in practice since $1665,{ }^{1}$ and is the simplest and time-tested cell-based therapy. It is now known that it is the stem cells within the blood transfused which make the most significant contribution to the therapeutic effect, and that these cells complete their life cycle and eventually die off. Since the stem cells in the small quantity of blood are relatively few, their function is of a passive nature wherein these stem cells and the mature cells in blood provide a transient support for a short duration after which the body's cells take charge of the function. ${ }^{6}$ That is probably why blood transfusion is not referred to as stem cell transplantation. However, a bone marrow transplant can be considered to be a stem cell transplant because the recipient has abnormal bone marrow as a result of chemotherapy or radiotherapy and has only the donor marrow to sustain life. ${ }^{2,8}$ Skin transplantation is a procedure in which the skin from one site on the body is harvested and transplanted to other body site in burns victims 
and in cosmetic procedures. ${ }^{3}$ Skin transplantation is one of the earliest clinical applications of stem cells, because it is these cells which repopulate the transplanted region of the body where mature skin cells have died naturally or been destroyed. ${ }^{4}$ Similarly, autologous transplantations of bone and other tissues from one part of the body to another ${ }^{34}$ to repair a nonunion defect or act as a filler are also categorized as cell transplant procedures and not as drugs.

Allogenic organ transplants have been in practice since 1905 when the first corneal transplantation was performed. ${ }^{35}$ Nowadays, when kidney, heart, lung, and pancreatic transplantation is performed, the organs are handled over a period of several hours outside the donor cadaver body until transplanted, and are kept at different temperatures immersed in nonphysiological and synthetic media to preserve viability of the cells until transplanted. ${ }^{36}$ These procedures use various preservation materials, solutions, and/or chemicals to ensure that the entire organ remains viable and can resume its physiological functions after transplantation into the recipient's body. However, the effects of the different types of solutions used for preservation/transportation on the cells and their influence on clinical efficacy in patients needs further extensive research. ${ }^{37,38}$ Preserving an organ which is a conglomeration of many different tissue types consisting of billions of cells, employing varied materials and methodologies of preservation for more than few hours is acceptable with limited or no studies of randomized trials on safety and efficacy. Therefore the same should be more acceptable in case of individual cells which have been handled in the laboratory in terms of processing and expansion using varied methodologies of preservation, transportation and processing as long as their phenotype and genotype are confirmed to be the same as the original cells harvested. There arises the question of the nature and efficacy of the new cells that have been born during transportation, preservation, processing, and in vitro expansion in a nonphysiological environment. Further, it must be noted that in organ transplantation, the physiological process of cell division continues between the time of harvest and transplantation, and those cells born of cell division while the organ is in transit still function in a manner beneficial to the recipient after transplantation. Thus, if organ transplants are to be considered as procedures, the same should apply to cell therapies.

Taking all these factors into account, it will be appropriate to consider a live autologous cell as a tool that can be used in cell therapy, similar to the clinical procedure of in vitro fertilization, in which a clinical obstetrician and an embryologist work as a team when collecting the male and female germ cells, storing them appropriately, fertilizing them in vitro, and then transplanting the embryo into a uterus. Along the same lines, cell biologists with the necessary expertise and training can collaborate with interested clinicians of the relevant specialty to accomplish cell-based therapies in a safe manner. Such collaboration would be relevant to autologous stem cells, the in vitro phenotypes and genotypes of which do not change when they are subjected to expansion procedures, while continuing to investigate and gather data on their known and unknown characteristics, as well as on functional outcomes based on experiments under varied in vitro conditions to clarify the uncertainties in cell-based therapies.

However, a dilemma may arise when considering the fact that some of these cells are also being used as vehicles for therapeutic drug delivery. For example, mesenchymal stem cells have been used as targeted gene delivery carriers. ${ }^{39,40}$ Various other cells have also been used for drug delivery because they enable sustained release of a drug, coupled with other advantages. ${ }^{41}$ In this situation, considering stem cell-based applications as procedures may not be appropriate, and a separate insight into such uses of cells may be needed, given that the discussion presented here focuses mainly on cells and stem cells being used after an in vitro expansion process without any genetic manipulation or use as adjuvants or catalysts for drug delivery. We emphasize that paper is concerned only with adult stem cells and does not include embryonic stem cells, which need further research and discussion among the scientific community to categorize them appropriately before establishing standards for safety and efficacy in clinical application.

Although the differences between cell-based and drugbased therapies have been explained, with a basic understanding that cell-based therapies are more heterogeneous and their effects may be more diverse than those found with drug-based therapies, the fact that drugs by their nature and actions are also diverse is not to be ignored. However, the main difference, as explained earlier, is that the ingredients involved in the manufacture of drugs, along with their properties, can be controlled relatively easily, whereas those of cells are beyond control, and this alone gives rise to a multitude of differences in terms of their in vivo action and adverse effects. This understanding is fundamental to the recognition that significant problems are likely to arise when cell therapy is compared with drug-based therapy.

\section{Conclusion}

Cell-based therapy is different from drug-based therapy in which a known chemical entity has a known therapeutic effect along with a recognized adverse event profile in patients 
with specific illnesses. The age-old cell-based therapies which have been in practice for decades, when analyzed at the molecular level with advanced tools should yield added information, but should not be confused with reproducible and laboratory-synthesized components because the multifunctional capability and potential of cells and their exact mechanisms of action are not fully understood. It would be appropriate at this time to consider live cells in a clinical setting as being similar to in vitro fertilization as a clinical procedure, keeping in mind the principle of primum non nocere ("first, do no harm"), so as not to make the symptoms of the disease more grievous than the cure.

\section{Acknowledgment}

The authors acknowledge the Loyola ICAM College of Engineering Technology and the Loyola Institute of Frontier Energy for their support of our research and the M/S Chennai Cell Cluster for technical advice.

\section{Disclosure}

The authors report no conflicts of interest in this work.

\section{References}

1. Basnet RB, Lamichhane D, Sharma VK. A study of blood requisition and transfusion practice in surgery at Bir Hospital. PMJN. 2009;9:14-19.

2. Chao NJ, Blume KG. Bone marrow transplantation. Part I - allogeneic. West J Med. 1989;151:638-643.

3. Tilney NL. Transplantation and its biology: from fantasy to routine. J Appl Physiol. 2000;89:1681-1689.

4. Alonso L, Fuchs E. Stem cells of the skin epithelium. Proc Natl Acad Sci U S A. 2003;100 Suppl 1:11830-11835.

5. Thomas E, Storb R, Clift RA, et al. Bone-marrow transplantation (first of two parts). N Engl J Med. 1975;292:832-843.

6. Hodby K, Pamphilon D. Concise review: expanding roles for hematopoietic cellular therapy and the blood transfusion services. Stem Cells. 2011;29:1322-1326

7. Till JE, McCulloch EA. A direct measurement of the radiation sensitivity of normal mouse bone marrow cells. Radiat Res. 1961;14:213-22.

8. The National Institutes of Health Resource for Stem Cell Research. Hematopoietic stem cells. Available from: http://stemcells.nih.gov/info/ scireport/chapter5.asp. Accessed December 17, 2012.

9. Steptoe PC, Edwards RG. Birth after the reimplantation of a human embryo. Lancet. 1978;2:366.

10. Hall S. Louise Brown, first test tube baby, is pregnant. The Guardian, 2006. Available from: http://www.guardian.co.uk/medicine/ story/0,,1817639,00.html. Accessed December 17, 2012.

11. Halme DG, Kessler DA. FDA regulation of stem-cell-based therapies. N Engl J Med. 2006;355:1730-1735.

12. Fink DW Jr. FDA regulation of stem cell-based products. Science. 2009;324:1662-1663.

13. Körbling M, Anderlini P. Peripheral blood stem cell versus bone marrow allotransplantation: does the source of hematopoietic stem cells matter? Blood. 2001;98:2900-2908.

14. Méndez-Ferrer S, Michurina TV, Ferraro F, et al. Mesenchymal and haematopoietic stem cells form a unique bone marrow niche. Nature. 2010;466:829-834.

15. Robey PG. Stem cells near the century mark. J Clin Invest. 2000;105: 1489-1491.
16. Valeri CR, Pivacek LE. Effects of the temperature, the duration of frozen storage, and the freezing container on in vitro measurements in human peripheral blood mononuclear cells. Transfusion. 1996;36:303-308.

17. Mannello F, Tonti GA. Concise review: no breakthroughs for human mesenchymal and embryonic stem cell culture: conditioned medium, feeder layer, or feeder-free; medium with fetal calf serum, human serum, or enriched plasma; serum-free, serum replacement nonconditioned medium, or ad hoc formula? All that glitters is not gold! Stem Cells. 2007;25:1603-1609.

18. Parson A. The long journey from stem cells to medical product. Cell. 2006;125:9-11.

19. Pal R, Hanwate M, Totey SM. Effect of holding time, temperature and different parenteral solutions on viability and functionality of adult bone marrow-derived mesenchymal stem cells before transplantation. J Tissue Eng Regen Med. 2008;2:436-444.

20. Zaim M, Karaman S, Cetin G, Isik S. Donor age and long-term culture affect differentiation and proliferation of human bone marrow mesenchymal stem cells. Ann Hematol. 2012;91:1175-1186.

21. Perin EC, Geng YJ, Willerson JT. Adult stem cell therapy in perspective. Circulation. 2003;107:935-938.

22. Watanabe T, Kajiume T, Takaue Y, et al. Decrease in circulating hematopoietic progenitor cells by trapping in the pulmonary circulation. Cytotherapy. 2001;3:461-466.

23. Borlongan CV, Hadman M, Sanberg CD, Sanberg PR. Central nervous system entry of peripherally injected umbilical cord blood cells is not required for neuroprotection in stroke. Stroke. 2004;35:2385-2389.

24. Siqueira RC, Voltarelli JC, Messias AM, Jorge R. Possible mechanisms of retinal function recovery with the use of cell therapy with bone marrowderived stem cells. Arq Bras Oftalmol. 2010;73:474-479. Portuguese.

25. Kerre TC, De Smet G, De Smedt M, et al. Both CD34+38+ and $\mathrm{CD} 34+38$ - cells home specifically to the bone marrow of NOD/LtSZ $\mathrm{scid} / \mathrm{scid}$ mice but show different kinetics in expansion. J Immunol. 2001;167:3692-3698.

26. WHO Media Centre. Fact Sheet on Medicines: safety of medicines adverse drug reactions. 2008. Available from: http://www.who.int/ mediacentre/factsheets/fs293/en/index.html. Accessed December 17, 2012.

27. Trujillo MH, Guerrero J, Fragachan C, Fernandez MA. Pharmacologic antidotes in critical care medicine: a practical guide for drug administration. Crit Care Med. 1998;26:377-391.

28. Jeffery ND, Smith PM, Lakatos A, Ibanez C, Ito D, Franklin RJ. Clinical canine spinal cord injury provides an opportunity to examine the issues in translating laboratory techniques into practical therapy. Spinal Cord. 2006; $44: 584-593$.

29. Bolognesi M, Sacerdoti D, Mescoli C, et al. Different hemodynamic patterns of alcoholic and viral endstage cirrhosis: analysis of explanted liver weight, degree of fibrosis and splanchnic Doppler parameters. Scand J Gastroenterol. 2007;42:256-262.

30. Pai M, Spalding D, Xi F, Habib N. Autologous bone marrow stem cells in the treatment of chronic liver disease. Int J Hepatol. 2012;2012: 307165 .

31. Suzuki K, Murtuza B, Fukushima S, et al. Targeted cell delivery into infarcted rat hearts by retrograde intracoronary infusion: distribution, dynamics, and influence on cardiac function. Circulation. 2004; 110(11 Suppl 1):II225-230.

32. Ahrlund-Richter L, De Luca M, Marshak DR, Munsie M, Veiga A, Rao M. Isolation and production of cells suitable for human therapy: challenges ahead. Cell Stem Cell. 2009;4:20-26.

33. Piacibello W, Gammaitoni L, Pignochino Y. Proliferative senescence in hematopoietic stem cells during ex-vivo expansion. Folia Histochem Cytobiol. 2005;43:197-202.

34. Myeroff C, Archdeacon M. Autogenous bone graft: donor sites and techniques. J Bone Joint Surg Am. 2011;93:2227-2236.

35. Moffatt SL, Cartwright VA, Stumpf TH. Centennial review of corneal transplantation. Clin Experiment Ophthalmol. 2005;33:642-657.

36. Southard JH, Belzer FO. Organ preservation. Аnпи Rev Med. 1995;46: 235-247. 
37. Demmy TL, Biddle JS, Bennett LE, Walls JT, Schmaltz RA, Curtis JJ. Organ preservation solutions in heart transplantation - patterns of usage and related survival. Transplantation. 1997;63:262-269.

38. Camacho VR, de Fraga RS, Cerski CT, de Oliveira JR, Álvares-daSilva MR. Relationship between ischemia/reperfusion injury and the stimulus of fibrogenesis in an experimental model: comparison among different preservation solutions. Transplant Proc. 2011;43:3634-3637.

39. Hu YL, Huang B, Zhang TY, Miao PH, Tang GP, Tabata Y, Gao JQ. Mesenchymal stem cells as a novel carrier for targeted delivery of gene in cancer therapy based on nonviral transfection. Mol Pharm. 2012;9: 2698-2709.
40. Hu YL, Fu YH, Tabata Y, Gao JQ. Mesenchymal stem cells: a promising targeted-delivery vehicle in cancer gene therapy. J Control Release. 2010;147:154-162.

41. Gutiérrez Millán C, Colino Gandarillas CI, Sayalero Marinero ML, Lanao JM. Cell-based drug-delivery platforms. Ther Deliv. 2012;3: $25-41$.

\section{Publish your work in this journal}

Stem Cells and Cloning: Advances and Applications is an international, peer-reviewed, open access journal. Areas of interest in stem cell research include: Embryonic stem cells; Adult stem cells; Blastocysts; Cordblood stem cells; Stem cell transformation and culture; Therapeutic cloning; Umbilical cord blood and bone marrow cells; Laboratory, animal and human therapeutic studies; Philosophical and ethical issues related to stem cell research. This journal is indexed on CAS. The manuscript management system is completely online and includes a quick and fair peer-review system. Visit http://www.dovepress.com/ testimonials.php to read real quotes from published authors.

Submit your manuscript here: http://www.dovepress.com/stem-cells-and-cloning-advances-and-applications-journal 